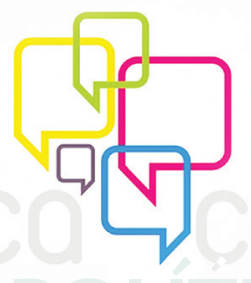

açãơ mididiática

N. 6 | Ano 2013

Universidade Federal do Paraná I Programa de Pós-Graduação em Comunicação

\title{
Perspectivas do campo criativo e as práticas institucionalizadas no Ensino Superior de criação publicitária ${ }^{1}$
}

\author{
Perspectives on the creative field and the institutionalized practices \\ of Higher Education in advertisement creation \\ Perspectivas del campo creativo y prácticas institucionalizadas \\ en la Educación Superior de la creación publicitaria
}

\author{
Juliana PETERMANN ${ }^{2}$ \\ Fábio HANSEN ${ }^{3}$ \\ Rodrigo Stéfani CORREA ${ }^{4}$
}

\begin{abstract}
RESUMO
Neste artigo daremos continuidade e amplitude a uma investigação que possui como preocupação central o ensino superior de criação publicitária e a sala de aula como campo de observação. O nosso objeto de estudo são as práticas pedagógicas de professores em disciplinas da área de criação publicitária. A ida a campo prevê a coleta de materiais didáticos e a gravação em áudio e vídeo de aulas de disciplinas cuja finalidade é o ensino de criação publicitária na Universidade Federal de Pernambuco (UFPE), na Universidade Federal de Santa Maria (UFSM) e na Universidade de São Paulo (USP). Como esta nova etapa da pesquisa está em fase inicial, a intenção aqui é compartilhar a essência da proposta da pesquisa, com hipóteses, resultados esperados e, em especial, o aporte teórico, construído sobre dois eixos: o dos conceitos de institucionalização de Berger e Luckmann (2008), e de habitus e dos capitais, a partir de Bourdieu.
\end{abstract}

Palavras-chave: Ensino; Criação Publicitária; Institucionalização; Recursos Metodológicos.

\begin{abstract}
In this article, we shall provide continuity and amplitude to an investigation which centers upon advertisement creation in higher education and upon the classroom as an observation field. Our study objects are the teaching practices of professors in modules related to advertisement creation. Our going to the field anticipates the collection of didactical materials and of the audio and video recording of modules whose goal is teaching advertisement creation at the Federal University of Pernambuco (UFPE), at the Federal University of Santa Maria (UFSM), and at the University of São Paulo (USP). As this new stage is still in its initial phase, our intention here is to share the essence of the research proposal through hypotheses, expected results, and, especially, through the theoretical framework, building upon two strands: Berger and Luckmann's concepts of institutionalization (2008) and Bordieu's habitus and capitals.
\end{abstract}

Keywords: Teaching; Advertisement Creation; Institutionalization; Methodological Resources.

1 Trabalho apresentado à sexta edição da Revista Ação Midiática - Estudos em Comunicação, Sociedade e Cultura, publicação ligada ao Programa de Pós-Graduação em Comunicação, da Universidade Federal do Paraná.

2 Professora Adjunta do Departamento de Ciências da Comunicação da Universidade Federal de Santa Maria. Doutora em Ciências da Comunicação pela Universidade do Vale do Rio dos Sinos (UNISINOS). jupetermann@yahoo.com.br

3 Docente na Escola Superior de Propaganda e Marketing (ESPM Sul). Doutor em Letras pela Universidade Federal do Rio Grande do Sul (UFRGS). fabiohansen@yahoo.com

4 Doutor em Comunicação e Semiótica pela Pontifícia Universidade Católica de São Paulo, atualmente dedica-se ao ensino de Criação Publicitária e aos Estudos de Mercado junto ao Departamento de Comunicação Social da Universidade Federal de Pernambuco. rodrigocorrea.ufpe@gmail.com 


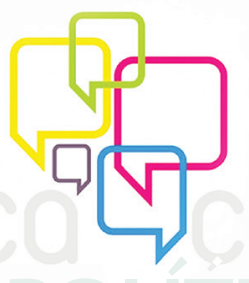

ação midiátitica

N. 6 | Ano 2013

Universidade Federal do Paraná | Programa de Pós-Graduação em Comunicação

\section{RESUMEN}

En este artículo vamos a seguir la amplitud de una investigación que tiene como su mayor preocupación la educación superior de la creación publicitaria y el aula como campo de observación. Nuestro objeto de estudio son las prácticas pedagógicas de los profesores en las disciplinas de la creación publicitaria. Yendo al campo establece la colección de materiales didácticos y de grabación de audio y video de las lecciones de disciplinas cuyo objetivo es la enseñanza de la creatividad publicitaria en la Universidad Federal de Pernambuco (UFPE), la Universidad Federal de Santa Maria (UFSM) y la Universidad de São Paulo (USP). En esta nueva etapa de la investigación se encuentra en su fase inicial, la intención aquí es compartir la esencia de la propuesta de investigación, con la hipótesis, los resultados y, en particular, la teórica, basada en dos ejes: la institucionalización de los conceptos de Berger y Luckmann (2008), y el habitus y el capital de Bourdieu.

Palabras clave: Enseñanza; Creación Publicitaria; Institucionalización; Recursos Metodológicos.

\section{Introdução}

Ao longo de três anos temos encaminhado nossas pesquisas para uma mesma direção, que propõe investigar o ensino superior de criação publicitária. Em 2011, mobilizamos (HANSEN, 2011) a noção de memória discursiva para avaliar o consumo dos saberes do mundo do trabalho publicitário em aulas de disciplinas cuja finalidade é o ensino de criação publicitária. Na ocasião, por meio de pesquisa documental, examinamos materiais que conduziram a difusão do saber nas disciplinas de Criação, Redação Publicitária e Direção de Arte na Escola Superior de Propaganda e Marketing (ESPM Sul).

No ano seguinte (HANSEN, 2012) estudamos, a partir da noção de formações imaginárias, o imaginário do professor sobre o mercado de criação publicitária e seus efeitos de sentido nas práticas pedagógicas. Por intermédio da gravação em áudio e vídeo de aulas de Criação, Direção de Arte e Redação Publicitária na ESPM Sul, atestamos que as formulações imaginárias que se manifestam nos procedimentos didático-pedagógicos desencadeiam um mundo do trabalho ideal e, por vezes, irreal, impactando na formação de um sujeito crítico.

Essa investigação preliminar serviu de alicerce para ir além. Logo, estamos dando seguimento à pesquisa iniciada e materializada nos textos supracitados. Sentimos a necessidade de avançar, pois chegar a conclusões, diagnósticos e propostas plausíveis requer tempo e um esforço consideravelmente maior e, certamente, a realização de muitas pesquisas. Por isso, o que se apresenta neste texto é outro passo na mesma direção. Propomos uma ampliação do campo de observação para projetar resultados que não se restrinjam apenas a um cenário regional e a instituições privadas. É nisso que consiste este artigo. Diante do que o trabalho de campo ${ }^{5}$ já tratou de revelar, julgamos prudente ampliar o corpus, permitindo,

5 Até agora o trabalho de campo se consumou em duas Instituições de Ensino Superior: Universidade de Santa Cruz do Sul (Unisc) e Escola Superior de Propaganda e Marketing (ESPM Sul). 


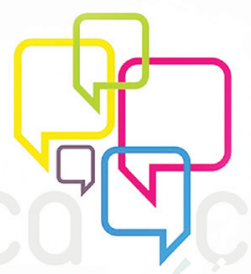

assim, comparar as práticas de ensino em Instituições de Ensino Superior de diferentes regiões do Brasil e, igualmente, Instituições de Ensino Superior públicas e privadas.

$\mathrm{Na}$ atual conjectura nos propomos a examinar os procedimentos didático-pedagógicos, as estratégias de ensino e as práticas docentes que são efetivadas no cotidiano da sala de aula, em algumas universidades brasileiras, constituindo, assim, uma pesquisa interinstitucional, que nesse momento, integra a Universidade Federal de Pernambuco (UFPE), a Universidade Federal de Santa Maria (UFSM) e a Universidade de São Paulo (USP).

\section{Ensino e Aprendizagem: um olhar sobre o ensino de comunicação}

O tema ensino de comunicação no Brasil não chega a se configurar em uma novidade na agenda de pesquisa. No que concerne ao ensino e aprendizagem, parece não haver escassez de referências. Porém, ao buscar estudos que preencham a lacuna do nosso objeto de estudo (ensino superior de criação publicitária) a bibliografia é extremamente limitada ${ }^{6}$. Por essa razão, para refletir sobre o ensino de comunicação, mais detidamente de publicidade, reunimos autores que tem contribuído com pesquisas científicas para o entendimento dos processos de ensino e aprendizagem, tanto no seu aspecto mais amplo como nas referências mais particulares ao campo da comunicação.

Na concepção de Costa (2010), a noção de educação tem sido reduzida a uma dimensão funcional, transformando o instrucionismo ${ }^{7}$ em "padrão intocável, sacralizando a transmissão copiada de conteúdos copiados" (DEMO, 2011, p. 8). No mesmo escopo, Citelli (2002) atesta que os processos de ensino e de aprendizagem precisam abandonar a concepção linear da mera transmissão de conteúdos e entender o conhecimento como processo social e em permanente construção. A preocupação com os aspectos instrumentais,lembra Lima (2011), tem conduzido a uma deformação na formação dos sujeitos. Para a autora, a decisão de limitar a educação superior a treinamento profissional implica consequências desastrosas na medida em que colabora para a centralização do processo educativo na obtenção do diploma e não na aprendizagem significativa e no desenvolvimento de competências humanas.

“Ensinar é promover a aprendizagem” (DEMO, 2011, p. 27). É muito mais que dar aula. Não há mais espaço para entrar em sala de aula e apenas dar aula, ignorando o aprendizado do aluno. Considerando que o processo de ensino impacta fortemente na aprendizagem dos estudantes, é tarefa docente, lembra Demo (2011), garantir aprendizagem adequada aos estudantes. Eis o que está em jogo e, aparentemente, não está sendo cumprido com eficiência no

6 A falta de bibliografia foi atestada em um levantamento dos estudos que têm sido realizados sobre o ensino superior em Publicidade e Propaganda no Brasil junto ao banco de dados de dissertações e teses da CAPES e, igualmente, na Scientific Electronic Library Online - SciELO, biblioteca eletrônica que abrange uma coleção selecionada de periódicos científicos brasileiros.

7 Termo utilizado pelo próprio autor ao referir-se a um processo de ensino linear de transferência de conhecimentos e não de uma construção de conhecimentos entre professor e estudantes. 

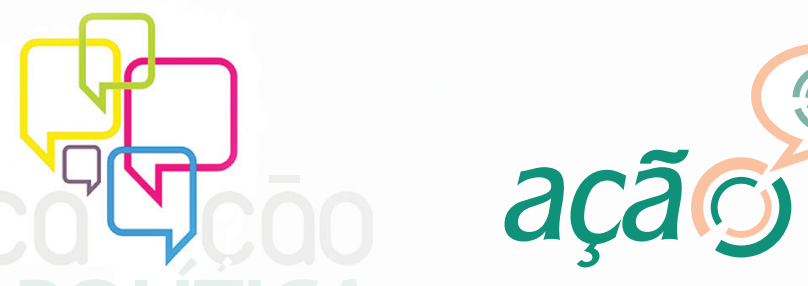

Estudos em Comunicação, Sociedade e Cultura

N. 6 | Ano 2013

Universidade Federal do Paraná | Programa de Pós-Graduação em Comunicação

campo da comunicação. Fígaro (2011) apurou que os profissionais de propaganda chegam ao mercado muito superficiais. São publicitários recém-saídos da graduação, com acesso a todas as tecnologias, mas sem profundidade. É um redator que pouco sabe escrever. Cria títulos, sacadas. Mas se atrapalha ao redigir um texto mais longo. Ou um diretor de arte que não faz um layout. Na opinião de Ferrentini (apud LIMA, 2011, p. 153), salvo honrosas exceções, os egressos oriundos da maioria das faculdades de Comunicação são muitos fracos, "não apenas do ponto de vista da capacitação técnica, mas essencialmente da condição cultural".

Para fugir de um modelo único de ensino e aprendizagem, evitando que todas as instituições tenham o mesmo objetivo e todos os alunos tenham que sair da mesma forma (DURHAM, 2007), muitos dos autores consultados apontam a necessidade de explorar a sala de aula como o lugar da experimentação. É o que indica, por exemplo, Ken Robinson (2010), professor inglês consultor de governos europeus. Para ele, "somos formados por um sistema educacional fast-food, em que tudo é padronizado, industrializado", e necessitamos aprender que o processo de ensino e aprendizagem não é um processo linear e mecânico, mas vivo. Robinson defende a adaptação da educação para diferentes circunstâncias, sob pena de o atual sistema sufocar a criatividade.

$\mathrm{Na}$ mesma linha de raciocínio, Gomes (2007) enxerga na universidade o verdadeiro lugar da inovação, de fugir das fórmulas prontas e repetitivas, do lugar-comum. De acordo com Machado; Martineli; Pinheiro (2010), a sala de aula é o "local privilegiado para propostas inquietantes e atitudes criativas", onde se deve ultrapassar a preparação técnica dos estudantes para seu ingresso no mercado de trabalho e proporcionar um ambiente de experimentação e reflexão, contrastando com a falta de tempo do mercado de trabalho.

Gomes (2007, p. 160) critica ambos os sujeitos participantes do processo de ensino e aprendizagem: "professores e alunos ficam deslumbrados com pouco, com o comum". Por essa razão, Tavares (2010, p. 3) sustenta que há o chamado "pacto da mediocridade", isto é, há um pacto na sala de aula, entre professor e alunos, e também no mercado, em "ser feliz fazendo o retrato do briefing". Isso gera dificuldades de criar possibilidades relevantes no ensino de criação publicitária, pois, conforme o autor, a fórmula mecânica de criação representa praticamente um modelo único, meramente formal e procedimental. Tavares (2010) classifica o ensino de criação publicitária como uma caricatura, representada por um professor que, segundo revelação do autor, normalmente divide os alunos da turma em poucos grandes grupos, para ter menos trabalho e dissolver a responsabilidade da criação publicitária, e ainda ausenta-se do processo criativo e aguarda a chegada de peças clichês e sua defesa.

Entretanto, acreditamos que o ensino de publicidade não deveria se limitar "à obediência de regras básicas ou normas técnicas", como cita Vitali (2007, p. 28) e tão pouco se restringir ao abstracionismo que concerne o ato institucional da criação. Nossa pesquisa é motivada pela inquietude e pelo prazer de ousar na direção de encontrar novas atitudes pedagógicas que 


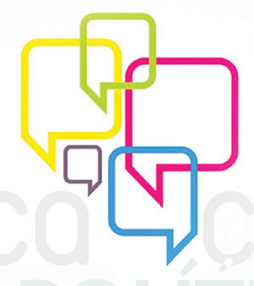

ação mididiática

N. 6 | Ano 2013

Universidade Federal do Paraná | Programa de Pós-Graduação em Comunicação

aumentem o campo de entendimento daquilo se qualifica como procedimentos criativos ou métodos didáticos para o ensino de publicidade.

No esforço de estabelecer o perfil docente demandado pela sociedade, Demo (2011, p. 38) diz: "o professor é da ordem da mediação" e para cumprir o papel de mediador deve ser capaz de equilibrar sensibilidade e técnica, pois sem o alargamento da sensibilidade o estudante não conseguirá abandonar o automatismo das decisões prontas, tornando-se um mero agente reprodutor (BACCEGA, 2002). Em sua nova função, é vital ao professor desenvolver a competência de ser um estimulador da busca e moderador das discussões. Ao mesmo tempo em que o diálogo e a troca de experiências reduzem a distância ${ }^{8}$ na relação professor-aluno, também exigem atenção mais voltada do docente ao aluno, além de sensibilidade e intuição para captar as suas dificuldades de aprendizado. Isso está ligado à metodologia e à didática, e a competência de planejar e avaliar permanentemente as rotinas pedagógicas.

A missão do educador é atuar mais como mediador do conhecimento, um condutor do aprendizado, parte chave de um processo educacional que permite ao estudante desenvolver competências mais amplas, como a autonomia, a criatividade inovadora, o trabalho em equipe, a curiosidade investigativa (REIMERS, 2011). Faz parte, ainda, do novo papel docente afastar-se "dos estereótipos reprodutivos de docentes empenhados em produzir alunos isentos de dúvidas" (DEMO, 2011, p. 25) e daqueles que engessam suas aulas deixando de discutir outros temas que surjam apenas porque desejam cumprir o roteiro previamente preparado.

Naturalmente, é prematuro supor que a conscientização do professor sobre a necessidade de se envolver na avaliação, na (re)elaboração e na execução de práticas pedagógicas constitui condição suficiente para que transformações aconteçam. Isso demanda tempo e estudo. Uma das dificuldades reside no fato de que nos acostumamos a fazer as coisas de certa forma. Depois de acostumados, a tendência é não conseguir ao menos perguntar se existem maneiras diferentes de fazer. De Nardi e Balzan (2010, p. 95) fazem alusão a um sujeito constituído "pelas/nas práticas que o dizem professor". Entendemos que se o professor souber que não há uma única forma de ensinar, isto já eleva, e muito, a possibilidade de rever conceitos tradicionais de ensino, a fim de reconfigurar práticas e espaços de aprendizagem (DE NARDI e BALZAN, 2010).

\section{Diferentes perspectivas sobre Criatividade}

Para pensar o ensino de criação publicitária necessitamos também retroceder e refletir sobre conceitos basilares que norteiam as práticas criativas não apenas na publicidade, mas

8 O ato de ensinar e aprender de forma horizontalizada é o que Paulo Freire defendia sob a denominação de "pedagogia sem hierarquia". "Quem ensina aprende ao ensinar e quem aprende ensina ao aprender", reflete Freire (1996) em sua obra "Pedagogia da Autonomia”. 

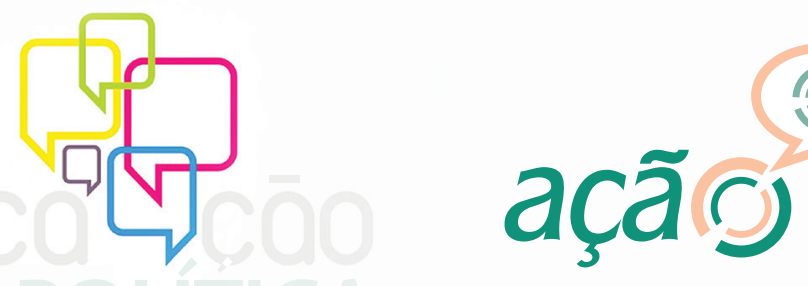

Estudos em Comunicação, Sociedade e Cultura

N. 6 | Ano 2013

Universidade Federal do Paraná | Programa de Pós-Graduação em Comunicação

em outras esferas, que, assim como na criação publicitária, também implicam em um espírito liberto e um grande emaranhado de referências. Apresentamos brevemente duas noções acerca da criatividade que nos parecem relevantes: uma com origem na psicologia, a partir de Winnicot (1975); e outra com origem na sociologia, a partir de Domenico De Masi (2000). Ambas são definitivas para iniciarmos uma investigação sobre o ensino de criação e sobre os modos como manejamos com nossas potencialidades criativas. Tanto o pensamento de Winnicot quanto de De Masi nos fazem refletir sobre as práticas de ensino de criação publicitária e o modo como, por vezes, condicionamos as situações em sala de aula. Acreditamos que no ambiente acadêmico possamos ir em busca de condições de criação mais próximas das ideais, na comparação ao mercado de trabalho.

As proposições de Winnicot são de referência geral à criatividade, mas podem ser pensadas para a criação publicitária, colaborando com nossas reflexões sobre o ensino desta prática. As preocupações deste autor são no sentido de evitar um desgaste dos termos criação/ criatividade ao serem utilizados apenas em relação à criação bem sucedida ou aclamada, significando-os como um colorido de toda a atitude com relação à realidade externa, constituindo um estado saudável de vida. Nesse sentido, mais do que pensar a criação atrelada às obras de arte, Winnicot (1975) propõe que pensemos a criação como um quadro, um jardim, um vestido, um penteado, uma sinfonia ou uma escultura, enfim, como todas as formas de manifestação da subjetividade do indivíduo.

Por isso, a criatividade pensada por meio desta perspectiva relaciona-se ao jogo que se faz entre a realidade interna e psíquica do sujeito e sua realidade externa: desde o momento da gestação, lidamos com o espaço entre: entre nós e o que somos e os limites impostos pela barriga de nossas mães. E já ali naquele espaço restrito colocamos em atuação nosso potencial criativo em busca pela sobrevivência.

Winnicot (1975) propõe uma sequência indicada para uso em sessões de análise, mas que para nós pode ser interessante para além de sua aplicação em consultórios. Para o autor, nessas condições altamente especializadas, o sujeito pode reunir-se e existir como unidade e como expressão e não unicamente como defesa contra a ansiedade. A sequência indicada pelo autor é a seguinte: (a) Relaxamento em condições de confiança baseada na experiência; (b) Atividade criativa, física e mental, manifestada na brincadeira; (c) A somação dessas experiências formando a base do sentimento do eu (self). O último estágio de somação exige um retorno, como espécie de feedback, daquele que ouve, seja o terapeuta, um amigo ou um professor.

O pensamento de Winnicot poderá ser demasiado útil na avaliação das práticas de ensino identificadas em nossa pesquisa. Parece-nos importante pensar as práticas criativas na publicidade, assim como o são tantas outras, até aquelas que parecem mais simples porque 


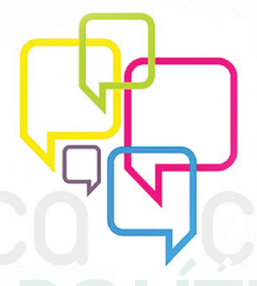

açãô Imidiática

N. 6 | Ano 2013

Universidade Federal do Paraná I Programa de Pós-Graduação em Comunicação

estão depositadas em atividades do cotidiano, mas dizem respeito a uma constante luta pela manutenção da vida.

Da mesma forma, encontramos também no pensamento sociológico de Domenico De Masi (2000) alternativas para refletir sobre a criatividade e sobre a criação publicitária, a partir de experiências mais generalistas, assim como também o fizemos a partir de Winnicot (1975). De Masi constitui a ideia do ócio criativo em um contexto de predominância do pensamento marxista, no qual se destacavam os estudos voltados para a questão do trabalho, dos conflitos, da organização produtiva, sindical e política da classe operária. A partir deste contexto - que possuía como agravante a filosofia inculcada pela religião de que apenas o trabalho dignifica o homem, responsável também pela construção de uma visão negativa do ócio - tornou-se necessário o estudo sobre a criatividade, pensada a partir de grupos criativos, e como uma síntese entre o consciente e o inconsciente e, ainda, entre a esfera racional e a emotiva. Para o autor, a esfera racional seria constituída pelo conjunto dos nossos conhecimentos e habilidades, enquanto que a esfera emotiva seria o conjunto das nossas opiniões, comportamentos, emoções e sentimentos.

Dessa forma, agrupando mentes mais racionais e outras mais emotivas, teríamos nem apenas fantasia, nem apenas concretude: teríamos o encontro com as soluções criativas e a capacidade de realizá-las mais facilmente. Dessa síntese é que De Masi propõe seu entendimento sobre o que é a criatividade: para ele tudo é parte de uma reelaboração pessoal de ideias que se originam coletivamente. Assim, criatividade é, ao mesmo tempo, heteropoiese e autopoiese: adquirimos materiais de outros (heteropoiese), mas estes são reelaborados até chegarmos a uma visão nova (autopoiese). Este autor propõe então que eduquemos para o ócio e para a criatividade: identificando uma vocação autêntica, sabendo escolher os parceiros adequados, criando um contexto propício à criatividade, descobrindo formas de explorar os vários aspectos do problema, relaxando a mente e estimulando-a até que surja uma boa ideia.

\section{Institucionalização, campo, habitus e os capitais}

Entendemos de antemão que o ensino em criação publicitária estabelece-se a partir de mecanismos de institucionalização, já que prevê regras e condutas definidas entre os sujeitos que ali se encontram e que, a partir de Berger \& Luckmann (2008), poderíamos denominar como papéis institucionais. Sabemos que professores e estudantes recebem, ainda que de forma inconsciente, fórmulas a serem seguidas e que estas, por sua vez, estão baseadas na atuação de outros atores, que também desempenham papéis institucionais: os profissionais da criação publicitária que, mesmo que localizados em um ambiente distante daquele do ensino superior de propaganda, possuem suas práticas comentadas, exemplificadas, criticadas e também reproduzidas neste ambiente. 


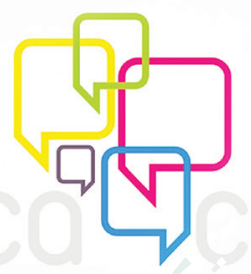

ação midiáática

N. 6 | Ano 2013

Universidade Federal do Paraná | Programa de Pós-Graduação em Comunicação

Os autores propõem então que uma análise resultante de uma teoria da institucionalização seria capaz de oferecer meios para o entendimento das causas que "conduzem à emergência, manutenção, e transmissão de uma ordem social” (BERGER \& LUCKMANN, 2008, p. 77). Tal ordem social seria então proveniente do hábito, considerado como inerente às atividades do homem: os autores dizem que a construção de padrões de reprodução permite maior eficiência às ações. Isso acontece em função do "importante ganho psicológico de fazer estreitarem-se as opções” (BERGER \& LUCKMANN, 2008, p.78).

Do contrário, para cada ação executada, por mais simples que ela fosse, teríamos que desenvolver métodos e técnicas para que obtivéssemos sucesso. Assim, organizamos tipificações, que compreendem, por vezes, normas, regras e modos de conduta que são internalizados e passíveis de reprodução. Neste momento, em que as ações habituais tornam-se tipificadas, configuram-se os processos de institucionalização. Temos interesse nestes processos que concernem ao ensino em criação publicitária e isto nos direciona para o segundo eixo teórico a ser tensionado em nossas análises: os conceitos de campo, de habitus e dos capitais, a partir de Bourdieu (1983 e 2004).

Como vínhamos dizendo, se identificamos modos de conduta específicos e papéis determinados, que atuam na criação publicitária e que são definitivos na área que constitui nosso objeto de investigação - o processo de ensino e aprendizagem em criação publicitária - não poderíamos desconsiderar tais noções. Identificamos a criação publicitária como um subcampo, integrante do campo ${ }^{9}$ da publicidade.

Assim, partimos das concepções de Bourdieu de que os campos apresentam leis gerais, e que estas podem ser homólogas entre os diferentes campos. Consideramos tais homologias e, portanto, apropriamo-nos de descrições feitas sobre outros campos e que podem revelar aspectos daquele que é de nosso interesse neste momento. Bourdieu diz ao considerar sobre o campo científico:

(...) propus a ideia de que o campo científico, tal como outros campos, é um campo de forças dotado de uma estrutura e também de um espaço de conflitos pela manutenção ou pela transformação desse campo de forças. (...) É na relação entre os diferentes agentes (concebidos como 'fontes de campo') que se engendra o campo e as relações de força que o caracterizam (relação de forças específica, propriamente simbólica, dada a 'natureza' da força capaz de se exercer nesse campo, o capital científico, espécie de capital simbólico que age na e pela comunicação). Mais exatamente, são os agentes, (...) definidos pelo volume e pela estrutura do capital específico que possuem, que determinam a estrutura do campo que os determina (BOURDIEU, 2004, p. 52-53).

O conceito de campo serve então para que pensemos o subcampo da criação publicitária

9 O conceito de campo será fundamental no transcorrer da pesquisa, até mesmo porque se apresenta como indispensável para que se considere a identificação de um habitus específico no ensino de criação publicitária. 


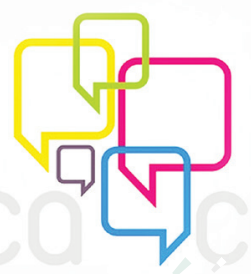

como um campo de forças que se estabelecem entre os agentes que ali atuam. Ainda, identificamos agentes, que atuam de modos específicos, organizando disputas que dizem respeito ao ensino dentro deste subcampo. Como agentes principais e determinantes para a constituição deste encontramos os professores, os jovens estudantes e futuros publicitários, e, ainda, aqueles que serão seus futuros colegas no mercado de trabalho.

Sabemos que cada um destes agentes possui modos de conduta determinados pelo próprio campo e ao que, ao mesmo tempo, o determinam. Tais modos de conduta são conceituados por Bourdieu (1983, p. 61) como disposições duráveis ou como um habitus:

\begin{abstract}
As estruturas constitutivas de um tipo particular de meio (as condições materiais de existência características de uma condição de classe), que podem ser apreendidas empiricamente sob a forma de regularidades associadas a um meio socialmente estruturado, produzem habitus, sistemas de disposições duráveis, estruturas estruturadas predispostas a funcionar como estruturas estruturantes, isto é, como princípio gerador e estruturador das práticas e das representações que podem ser objetivamente 'reguladas' e 'regulares' sem ser o produto da obediência a regras, obviamente adaptadas a seu fim sem supor a intenção consciente dos fins e o domínio expresso das operações necessárias para atingi-los e coletivamente orquestradas, sem ser o produto da ação organizadora de um regente.
\end{abstract}

Certamente em nossa pesquisa teremos de considerar o habitus do subcampo atuando em e sobre cada um dos agentes de modo específico; e mesmo que encontremos conformidades, também identificaremos pontos de diferenciação entre eles. Até mesmo porque cada um destes agentes atuará mediante uma desigual distribuição dos capitais: social, econômico, cultural e simbólico. E tal distribuição desigual é determinante das lutas internas no campo, e que determinam sua própria estrutura, e, por isso, certamente será reveladora das questões que procuramos verificar e que estão pautadas também sobre as disputas entre professores e estudantes e entre ambos e os que se encontram no mercado publicitário.

De acordo com Bourdieu (2004, p. 53) tal distribuição desigual dos volumes dos capitais é o que define também posições diferentes dos agentes no campo: "dominante é aquele que ocupa na estrutura uma posição tal que a estrutura age em seu favor". Assim, os movimentos internos dos campos são definidos pela aquisição ou pelo aumento do volume dos capitais, ou o que ele chama de armas e trunfos específicos, e a diferenciação se dá pela posse ou não de poder, comparado a uma forma de energia social.

A partir dos discursos e da análise das práticas de ensino em criação publicitária temos a intenção de identificar como ocorrem tais disputas e como se concentram os níveis dos diferentes capitais no subcampo. Certamente, esta perspectiva será bastante reveladora das problemáticas e das potencialidades de nosso objeto de investigação - o ensino de criação publicitária. 


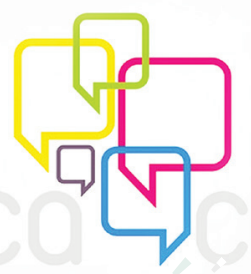

\section{Os recursos metodológicos a serem empregados na pesquisa}

Tradicionalmente figuram nos currículos dos cursos de graduação em Comunicação Social, habilitação em Publicidade e Propaganda, as disciplinas de Criação, Redação Publicitária e Direção de Arte dentre aquelas que constituem a base de formação para a área de criação. A elas costumam se resumir os conteúdos trabalhados para preparar o novo profissional criativo. Porém, além dos conteúdos programáticos, queremos entender como estamos formando - por meio de quais práticas pedagógicas e métodos de ensino - os estudantes da área criativa.

Diante de objeto tão complexo quanto o que pretendemos investigar, e que podemos designar como o processo de ensino e aprendizagem de criação publicitária, conduziremos a pesquisa de modo cartográfico.

Em linhas gerais, trata-se sempre de investigar um processo de produção. De saída, a ideia de desenvolver o método cartográfico para utilização em pesquisas de campo no estudo da subjetividade se afasta do objetivo de definir um conjunto de regras abstratas para serem aplicadas. Não se busca estabelecer um caminho linear para atingir um fim. A cartografia é sempre um método ad hoc. Todavia, sua construção caso a caso não impede que se procure estabelecer algumas pistas que têm em vista descrever, discutir e, sobretudo, coletivizar a experiência do cartógrafo (KASTRUP, 2007, p. 16).

$\mathrm{Na}$ configuração do trabalho de campo, definimos as seguintes técnicas e passos metodológicos organizados a partir da disposição cartográfica. Foram selecionadas ${ }^{10}$ três Instituições de Ensino Superior (UFPE, UFSM e USP) e seus cursos de graduação em Comunicação Social: Publicidade e Propaganda. As disciplinas da área de criação publicitária foram escolhidas dentre aquelas que constam nas grades curriculares. São elas Redação Publicitária e Direção de Arte. O recorte das disciplinas de formação em criação independe do nome, pois ele se altera de instituição para instituição. O critério de uniformidade que pesou na escolha das disciplinas reside no fato de a ementa abordar as competências aplicadas de direção de arte e redação publicitária.

Serão acompanhadas durante dois semestres, por meio de gravação em áudio e vídeo, aulas expositivas e, no mínimo, uma atividade prática na disciplina, com os seus prováveis momentos: a) passagem das instruções da atividade prática (trabalho) por parte do professor; b) orientações individuais ou coletivas do professor aos estudantes; c) defesa/apresentação do trabalho por parte dos estudantes aos seus colegas de turma e ao professor. Além da gravação

10 A escolha das três Instituições de Ensino, assim como ocorreu quando da opção pela Unisc e pela ESPM Sul na pesquisa anterior, deu-se pelo critério de disponibilidade e conveniência, isto é, acesso e proximidade dos pesquisadores com as Instituições e seus representantes. Todavia, cabe enfatizar que a disponibilidade e a conveniência não foram as únicas variáveis consideradas. Houve a nítida preocupação em contemplar instituições públicas (federais e estaduais), uma vez que na investigação anterior a coleta aconteceu em instituições privadas. Igualmente, pesou a intenção de ampliar o campo de observação para além do regional. 


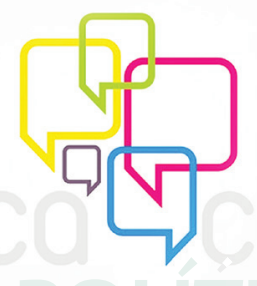

\section{ação}

Estudos em Comunicação, Sociedade e Cultura

N. 6 | Ano 2013

Universidade Federal do Paraná I Programa de Pós-Graduação em Comunicação

das aulas expositivas e práticas, outra técnica de coleta de dados será empregada: a pesquisa documental. Reuniremos planos de ensino (com ementa, conteúdo programático, métodos de ensino e sistemas de avaliação, bibliografia indicada), provas, trabalhos solicitados aos estudantes, devolutivas/feedbacks, materiais didáticos (textos para discussão, briefings).

Quanto à materialidade discursiva utilizada para fins de análise, constituiremos a montagem do arquivo discursivo a partir do registro das produções discursivas de professores e estudantes de disciplinas da área de criação publicitária da UFPE, UFSM e da USP para, ao término da execução da pesquisa, colocá-los em perspectiva aos dados já produzidos no trabalho de campo na Unisc e na ESPM Sul. Ou seja, examinaremos o processo de ensino e aprendizagem de criação publicitária por meio dos diálogos internos da sala de aula, a partir dos registros das atividades desenvolvidas e dos materiais utilizados e produzidos.

\section{Considerações preliminares sobre o ensino de criação publicitária}

A criação publicitária sempre foi uma atividade antes prática do que teórica e seu ensino mais técnico do que reflexivo (GOMES, 2008, p. 111). A autora afirma que embora grande parte dos nossos docentes manifeste preocupação com a necessidade de aumento das "discussões teóricas para que o profissional egresso tenha uma atitude mais reflexiva e crítica", ainda prevalecem as disciplinas técnicas sobre as teóricas nos currículos dos nossos cursos. As instituições de ensino permanecem obcecadas com as habilidades acadêmicas e apegadas as pedagogias tecnicistas - tão criticadas por Paulo Freire -, formando cidadãos previsíveis. Diante disso, perguntamos: o que tem sido feito para pensar criticamente a formação em publicidade e propaganda? Já tarda o momento de (re)pensarmos a formação do profissional de publicidade e propaganda e nos questionarmos: há deformação na formação?

De maneira geral, ainda predomina um formato conservador de ensino. $\mathrm{Na}$ avaliação do ensino de criação publicitária pressupomos que as metodologias que organizam as práticas criativas, os modos de estruturação das aulas e os papéis que ali se estabelecem constituem as instituições de ensino superior de publicidade e propaganda e obedecem aos lugares de institucionalização, a partir do que apontam Berger \& Luckman (2008). Diríamos, unindo-nos a Pêcheux (1997), que a relação de forças em que o discurso é situado intervém veementemente. E o espaço discursivo da sala de aula é um espaço institucionalizado, em que professor e estudante se inscrevem. A reflexão sobre o ensino de criação publicitária inclui a necessidade de considerar as posições discursivas que os sujeitos ocupam. "Não importam os lugares empíricos" (ORLANDI, 2001, p. 40), mas a posição que ocupam, ou imaginam que ocupam. Para Orlandi (1987), ancorado em um saber incontestável, o professor pode influenciar o aluno a não questionar e discutir. Simplesmente receber e assimilar. O professor é o detentor do saber, e o aluno só terá acesso a ele por meio da submissão à autoridade docente. A voz do professor 

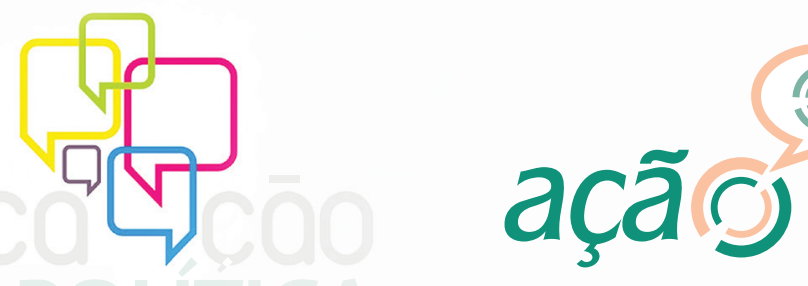

Estudos em Comunicação, Sociedade e Cultura

N. 6 | Ano 2013

Universidade Federal do Paraná | Programa de Pós-Graduação em Comunicação

dá a direção de sentidos que o aluno deve seguir. O professor é institucional e idealmente aquele que possui o saber e está na escola para ensinar, enquanto o aluno é aquele que está na escola para aprender (ORLANDI, 1987).

Por atacado, resta pouco lugar para o inesperado, o original e o inovador. A escola ainda tem dificuldade de entender o papel fundamental que exerce no aprendizado do pensar além do convencional. "O atual sistema educacional mata a criatividade", indica Robinson (2010). Na mesma direção, Vitali (2007, p. 27) reivindica uma "ação educacional para desenvolver capacidades inovadoras, criativas e críticas". Acrescentamos, de imediato, que é imprescindível, em meio ao processo educacional, facultar ao estudante gerar competências como autonomia, convivência interpessoal e criatividade. Mas como estamos desenvolvendo a competência chamada "criatividade" nos estudantes?

Poderíamos dizer, juntamente com Winnicot (1975), que é importante utilizar o lúdico em sala de aula para ativar a criatividade. O autor relaciona a criatividade ao ato do brincar e considera que é somente no brincar que uma criança ou um adulto podem ser criativos. Assim, o ato do brincar torna-se uma possibilidade concreta de fruição da liberdade de criação. Entendemos que o ponto de vista da psicologia pode auxiliar na seguinte reflexão: quanto nossas salas de aula não constrangem o processo criativo? Oportunizamos aos estudantes espaços de liberdade que possibilitem práticas criativas? De que forma conseguimos estabelecer momentos e espaços lúdicos em sala de aula para ativar a criatividade?

Se o sistema educacional ainda precisa avançar para se tornar um espaço estimulante e inspirador no processo formativo, soa como um alento a identificação da aproximação da escola em relação às linguagens que Citelli (2002) chama de não escolares. Tal afirmação abre passagem para acreditarmos em novas proposições didáticas para o ensino de publicidade, a fim de reconfigurar o cenário da aprendizagem, e transformar a sala de aula em um espaço variado de aprendizagem e recheado de ludicidade. O desafio de introduzir o caráter lúdico à sala de aula dialoga com a noção de aprendizagem distraída proposta por Sartori (2010, p. 47). Conforme a autora, a escola precisa estar preparada para "lidar com a observação distraída, que proporciona aprendizagens na diversão; com as aprendizagens construídas em contato com novas linguagens". Em tom semelhante, Demo (2011) sugere o incremento de modos não formais de aprender para pleitear a aprendizagem crítica e criativa e, por extensão, forjar autonomia. Por isso, os novos modos de aprender precisam ser projetados na perspectiva de motivar o estudante a reconstruir conhecimentos e fomentar nele a autoria individual e coletiva, além de estimular a observação e a curiosidade.

Por sua vez, a noção de aprendizagem distraída não está distante da teoria do brincar criativo de Winnicot (1975), para quem a restrição às atividades lúdicas e a escassez de brincadeiras acarreta na perda da espontaneidade e do impulso criativo. De acordo com Winnicot 

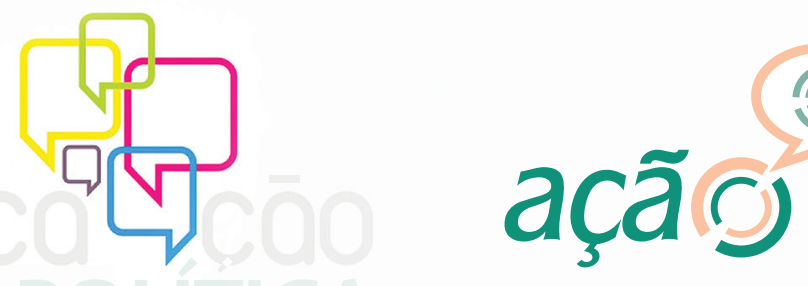

Estudos em Comunicação, Sociedade e Cultura

N. 6 | Ano 2013

Universidade Federal do Paraná | Programa de Pós-Graduação em Comunicação

(1975), o brincar está diretamente associado a uma experiência criativa intensamente real para o sujeito, e o brincar criativo só se origina de um estado relaxado, o que implica em um espírito liberto para manejar as potencialidades criativas. No entanto, para alcançarmos este estágio, é importante fomentar condições favoráveis em sala de aula, preferencialmente tirando vantagem do fato de estarmos imersos em um "ambiente educativo difuso e descentralizado" (SARTORI, 2010, p. 40).

A partir das hipóteses aqui levantadas - o investimento das instituições de ensino em uma pedagogia expressiva onde situações e atividades lúdicas estejam presentes em sala de aula é um caminho para superar o que é hoje um espaço fortemente institucionalizado e com posições cristalizadas - procuramos discutir questões relativas ao processo de ensino e aprendizagem de criação publicitária. Assim, pleiteamos aqui questionar as práticas pedagógicas vigentes nas disciplinas da área de criação publicitária.

Cremos que os referenciais teóricos que encampam conhecimento do campo educacional, publicitário (criatividade e processos de criação), sociologia (conceitos de Bourdieu, 1983 e 2004) e análise do discurso de corrente francesa são essenciais para se perseguir os objetivos propostos e, em tese, apontam para uma pesquisa que pode inaugurar, de fato, uma discussão sobre as práticas pedagógicas de criação publicitária no Brasil e contribuir para o surgimento de novas propostas no ensino e na aprendizagem de criação publicitária para as escolas de propaganda em geral.

Outros sim, talvez conseguiremos gerar apenas um alerta para o campo publicitário, uma vez que a mudança na forma de ensinar tais disciplinas enfrenta ainda o forte paradigma mecanicista e, para vencê-la, é preciso uma modificação da estrutura curricular dos cursos, suprainstitucional, envolvendo as instituições de ensino e o MEC. A despeito das transformações curriculares necessárias, da resistência das instituições de ensino e da falta de vontade política do MEC, a mudança na forma de ensinar criação publicitária tem no professor, na sua didática, na metodologia que adota e nas estratégias de ensino que emprega, o seu agente principal.

Pretendemos que a reflexão proposta se constitua em uma contribuição para estudantes, professores, pesquisadores e profissionais se familiarizarem ao funcionamento do ensino de criação publicitária. À medida que a área acadêmica de publicidade e propaganda é, segundo Gomes (2007), carente de debates, o estudo é relevante e atual, uma vez que poderá auxiliar o mercado publicitário a entender como as escolas de comunicação estão formando os estudantes: as práticas pedagógicas, os conteúdos programáticos, as técnicas de ensino, os saberes didáticos.

Até aqui renovamos a impressão de que não se aprende sobre educação somente com livros, mas conhecendo as questões cotidianas da sala de aula, produzindo conhecimento com base na vivência da prática de ensino. Ou seja, sem menosprezo à abordagem teórica, o diferencial da nossa pesquisa está na perspectiva empírica diante da falta de dados sobre a 


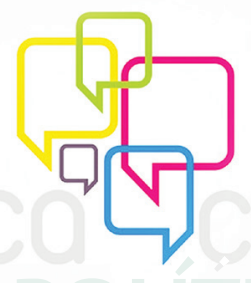

ação) Imidiática

N. 6 | Ano 2013

\section{Universidade Federal do Paraná I Programa de Pós-Graduação em Comunicação}

ação educativa em sala de aula. Por isso nos interessa penetrar neste espaço "sagrado" não (ou pouco) observado.

Assim, por último, gostaríamos de enfatizar que este estudo prolonga-se na análise dos procedimentos didático-pedagógicos empregados por professores, quando identificaremos se há, nas Instituições de Ensino Superior investigadas, práticas pedagógicas, estratégias de ensino e experiências de aprendizagem inovadoras. Neste momento futuro de nossa pesquisa, objetivaremos a proposição de alternativas e possibilidades didáticas no ensino da área da criação publicitária.

\section{Referências}

BACCEGA, Maria Aparecida (org.). Gestão de processos comunicacionais. São Paulo: Atlas, 2002.

BERGER, Peter; LUCKMANN, Thomas. A construção social da realidade. São Paulo: Vozes, 2008.

BOURDIEU, Pierre. Sociologia. São Paulo: Ática, 1983.

Para uma sociologia da ciência. São Paulo: Edições 70, 2004.

CITELLI, Adilson. Comunicação e Educação: aproximações. In: BACCEGA, Maria Aparecida. Gestão de processos comunicacionais. São Paulo: Atlas, 2002, p. 101-112.

COSTA, Belarmino César. Comunicação e educação na era digital: reflexões sobre estética e virtualização. In: Comunicação, Mídia e Consumo - Revista do Programa de Mestrado em Comunicação e Práticas de Consumo da Escola Superior de Propaganda e Marketing, v. 7, n. 19, São Paulo, jul. 2010, p. 87-103.

DE MASI, Domenico. O ócio criativo. São Paulo: Sextante, 2000.

DEMO, Pedro. Outro professor: alunos podem aprender bem com professores que aprendem bem. Jundiaí: Paco Editorial, 2011.

DE NARDI, Fabiele S.; BALZAN, Fabíola P. Relações entre cultura e ensino: um olhar discursivo sobre as políticas públicas para formação de professores. IN: Organon - Revista do Instituto de Letras da Universidade Federal do Rio Grande do Sul, v. 24, n. 48, Porto Alegre, janeiro-junho, 2010, p. 87-102.

DURHAM, Eunice Ribeiro. A qualidade do ensino superior no Brasil. In: KUNSCH, Margarida M. Krohling (Org.). Ensino de Comunicação: qualidade na formação acadêmico-profissional. São Paulo: ECA-USP: Intercom, 2007, p. 23-32. 

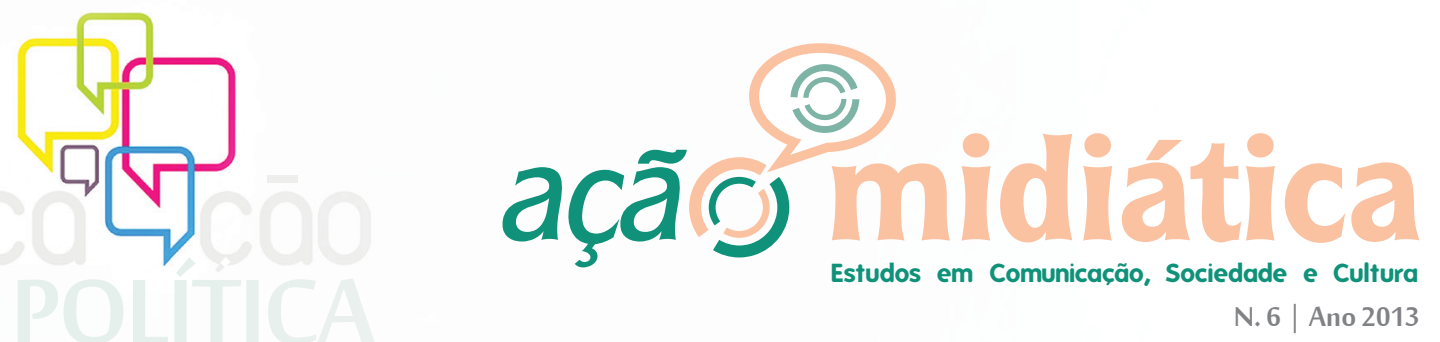

N. 6 | Ano 2013

Universidade Federal do Paraná | Programa de Pós-Graduação em Comunicação

passado. Carta Escola, São Paulo, ano 26. n. 243, p. 32-34, jun./jul. 2011

ROBINSON, Ken. A escola mata a criatividade. Istoé, 23 jun. 2010. Disponível em: $<\underline{\text { http:// }}$ www.istoe.com.br>. Acesso em: 23 de jun. 2010.

SARTORI, Ademilde Silveira. Educomunicação e sua relação com a escola: a promoção de ecossistemas comunicativos e a aprendizagem distraída. In: Comunicação, Mídia e Consumo - Revista do Programa de Mestrado em Comunicação e Práticas de Consumo da Escola Superior de Propaganda e Marketing. v. 7, n. 19, São Paulo, jul. 2010, p. 33-48.

TAVARES, Dirceu. Conceito de interatividade no ensino da publicidade. Anais do XXXIIII Congresso Brasileiro de Ciências da Comunicação, 2010.

VITALI, Tereza Cristina. O desafio do ensino superior de Publicidade para o século XXI. In: PEREZ, Clotilde; BARBOSA, Ivan Santo (Org.). Hiperpublicidade: fundamentos e interfaces. v. 1. São Paulo: Thomson Learning, 2007, p. 14-31.

WINNICOT, D. W. O brincar e a realidade. Rio de Janeiro: Imago, 1975. 